\title{
CONSÓRCIOS INTERMUNICIPAIS DE SAÚDE: UMA REFLEXÃO SOBRE A DICOTOMIA ENTRE ADMINISTRAÇÃO PÚBLICA E PRIVADA
}

\author{
MENDES, Wanderson de Almeida ${ }^{1}$ \\ MENDES, Wesley de Almeida ${ }^{2}$ \\ MAGALHÃES, Fernanda Gabriela Gandra Pimenta ${ }^{3}$ \\ HORSTH, Tarrara Alves
}

RESUMO: A administração como ciência surge dos moldes empresariais para racionalizar o trabalho. Por outro lado, o setor público, ambiente mais complexo e com escassez de recursos, tomou tais modelos como forma de gerenciar as ações públicas. Considerando ainda o serviço público de saúde, como um sistema de alta complexidade e necessidade para a sociedade, o presente estudo tem como objetivo fazer uma reflexão sobre a dicotomia entre administração pública e administração privada, buscando compreender o contexto da administração dos Consórcios Intermunicipais de Saúde (CIS), considerando ainda, as possíveis consequências da gestão inadequada desse tipo de Consórcio. Diante do exposto, pode-se perceber a importância da formação dos CIS no combate à precariedade do acesso ao atendimento da população que busca por tratamento de saúde mais rápido e de mais qualidade. Contudo, mesmo com a formação dos CIS, a área de saúde pública ainda sofre com muitas limitações. Dessa forma, percebe-se que apesar desses consórcios contribuírem para a minimização dos problemas relacionados à saúde pública, ainda se está longe da solução, devido à complexidade de tais problemas.

Palavras-chave: Administração. Redes. Saúde Pública.

SUMMARY: Management as a science emerges from the business model to rationalize work. On the other hand, the public sector, a more complex and resource-scarce environment, has taken such models as a way of managing public actions. Considering also the public health service, as a system of high complexity and necessity for society, the present study aims to reflect on the dichotomy between public administration and private administration, seeking to understand the context of Intermunicipal Health Consortiums administration, considering also, the possible consequences of improper management of this type of Consortium. In view of the above, it is possible to perceive the importance of the formation of the Intermunicipal Health Consortiums in combating the precariousness of the access to the service of the population that seeks for health treatment faster and of more quality. However, even with the formation of Intermunicipal Health Consortiums, the public health area still suffers from many limitations. Thus, although these consortia contribute to the minimization of problems related to public health, it is still far from the solution due to the complexity of such problems.

Keywords: Administration. Networks. Public Health.

\section{INTRODUÇÃO}

Este ensaio teórico trata dos Consórcios Intermunicipais de Saúde (CIS), que são uma forma de cooperação em rede entre municípios a fim de buscar, através de ações conjuntas, por melhoria da qualidade e do atendimento à população na área da saúde. Por meio deste tema, busca-se refletir sobre a dicotomia entre a administração no setor público e no setor privado.

Primeiramente, a fim de compreender a administração, deve-se retomar sua contextualização histórica. Os estudos sobre administração têm início na Administração Científica, com Frederick Taylor em seus estudos focados na busca por eficiência do trabalho, e em seguida a Administração Clássica de Henri Fayol, com pesquisas sobre a divisão do trabalho e a criação de cinco funções administrativas: planejar, organizar, comandar, controlar e coordenar (POCCC) (SOBRAL; PECI, 2008). Tais ideias

\footnotetext{
${ }^{1}$ Mestrando em Administração - Universidade Federal de Viçosa

${ }^{2}$ Doutorando em Administração - Universidade Federal de Viçosa

${ }^{3}$ Mestre em Administração - Universidade Federal de Viçosa
} 
contribuíram consideravelmente em relação ao desenvolvimento industrial, ao aumento de consumo, crescimento da economia e para a expansão do capitalismo, e que estão presentes ainda na atualidade (BRAVERMAN, 1977). Mais tarde, estudos de Elton Mayo sobre o comportamento humano, revelaram a importância dos fatores sociais a ponto de influenciar o trabalho, contrapondo sua teoria com os estudos da Administração Clássica (CHIAVENATO, 2003).

Contemporâneo de Mayo, Chester Barnard escreveu, no final da década de 1930, em sua obra "The functions of the executive" algumas funções que o executivo deveria desempenhar, e a organização surge como importante elemento, e que considera a existência da organização a partir do momento em que as pessoas são capazes de interagirem e estão dispostas a cooperarem para atingir um mesmo propósito (LODI, 1971). A gênese da Teoria das Organizações se dá na década de 1950, com os estudos de H. Simon e participação de psicólogos e sociólogos, nos Estados Unidos (FRANÇA FILHO, 2004).

Retomando este contexto histórico, pode-se perceber a presença da racionalidade instrumental nas raízes da administração, fazendo-se presente desde o início de seu desenvolvimento até os dias atuais, o que torna difícil o rompimento com este tipo de racionalidade. Esses estudos foram importantes para o desenvolvimento e sobrevivência das empresas, na criação de ferramentas gerenciais, contribuindo para o aumento de capacidade competitiva.

Por outro lado, a administração pública trabalha com um ambiente mais complexo que as empresas, devendo atender as demandas sociais que são crescentes frente à escassez de recursos, onde impera sobre o Estado a necessidade de criar mecanismos e estratégias à fim de atender seus objetivos e sanar as necessidades sociais.

Desse modo, o governo busca atender às necessidades da sociedade através da implementação de políticas públicas, visando a melhoria do bem-estar social. No entanto, por vezes o governo tem dificuldades em atender à imensa gama de demandas sociais, o que exige que este conceba meios alternativos de atender as necessidades da sociedade.

Na contramão do contexto de um mercado cada vez mais competitivo e de uma sociedade cada vez mais complexa, que criaria um ambiente propício ao individualismo, surge a ideia de cooperação. Nesta concepção, as organizações se juntam com objetivo de racionalizar seus recursos para atingirem um objetivo em comum, formando redes organizacionais, presentes tanto no setor privado, como no público, criando uma nova economia, onde os atores estão interligados, trocando informações e interesses (CASTELLS, 1999). Para Axelrod (1984), a busca por interesses individuais leva a cooperação entre pessoas, na tentativa conseguir atingir seus objetivos particulares.

Nessa perspectiva de cooperação, municípios a princípio com dificuldades de atender a tais demandas supra relatadas e a fim de sanar necessidades e interesses próprios, buscam parcerias com outros municípios, normalmente vizinhos, que tenham necessidades e dificuldades semelhantes. Formam-se assim os consórcios intermunicipais, que visam criar meios para aquisição e oferta de equipamentos e serviços, muitas vezes onerosos para o custeio de um único município. Esta foi a estratégia adotada pelos municípios na área da saúde, ao identificarem que embora determinados serviços nesta área possam apresentar baixa demanda, como serviço de prestação essencial, a necessidade de sua prestação é inegável dentro de um serviço público.

Assim, firmaram-se os CIS, com objetivo de amenizar os problemas com relação ao atendimento de saúde. Para Lima (2000), essas redes organizacionais de saúde contribuem para atendimentos relacionados ao bem-estar da sociedade, desde os níveis mais básicos até os mais complexos.

No entanto, compreender as particularidades dos atores envolvidos nos CIS, assim como a complexidade da sociedade, torna o papel de sua gestão um processo desafiador. Nesse contexto, surge a seguinte inquietação: como se compreender as redes organizacionais formadas no setor 
público considerando os consórcios intermunicipais de saúde?

Assim, este ensaio teórico tem como objetivo fazer uma reflexão sobre a dicotomia entre administração pública e administração privada, buscando compreender o contexto da administração dos CIS, considerando ainda, as possíveis consequências da gestão inadequada desse tipo de Consórcio.

As discussões aqui apresentadas visam contribuir para a literatura ao ponto de indicar uma discussão a respeito da forma de consórcios para a gestão pública, considerando a necessidade em atender as demandas sociais bem como entender que a escassez de recursos implica na necessidade de implantar um sistema mais eficiente de gestão. Os consórcios intermunicipais, assim, representam um importante modelo de gestão que visa incorporar os esforços de diferentes realidades municipais.

Para a elaboração deste trabalho e especificação das temáticas tratadas, o presente ensaio está dividido em cinco seções, iniciando-se por esta introdução. O próximo tópico discute as diferenças entre a administração no setor público e no setor privado, buscando compreender se realmente há uma dicotomia. A seção três, aborda as redes organizacionais e a quatro discute o que se trata dos CIS, sua administração e estrutura. $\mathrm{O}$ último tópico se refere à conclusão desta análise, fazendo uma reflexão da proposta desta discussão.

\section{A DICOTOMIA ENTRE ADMINISTRAÇÃo PÚBLICA E ADMINISTRAÇÃo NO SETOR PRIVADO}

Os estudos em administração surgem no final do século XIX e início do século XX com moldes na administração empresarial, com o modelo de administração científica proposta por Taylor e em seguida pelo modelo clássico proposto por Fayol (SOBRAL; PECI, 2008). No entanto, tanto a abordagem científica de Taylor quanto a abordagem clássica de Fayol foram desenvolvidas no setor privado. Tais abordagens, assim como a história da ciência administrativa, influenciadas por uma vertente positivista, contribuíram para o desenvolvimento dos estudos sobre administração. Contudo, existe a necessidade de estudos mais amplos, para o desenvolvimento de uma ciência mais adequada às necessidades sociais do que as propostas da ciência normal (SILVA; MATTIA, 2016).

Considerando a necessidade em se implantar um sistema mais eficiente, atendendo com maior qualidade as necessidades sociais bem como mantendo um controle dos recursos e aprimoramento das ações do Estado, a administração pública adotou algumas abordagens daquelas provenientes da administração empresarial, pautada em um sistema de negócios. Destacaram, nesse caso, o New Public Management (Nova Administração Pública - NPM) e o Reinventando o Governo, o último proposto por Osborn e Gable (FREDERICKSON, 1996).

O NPM trata-se de um modelo de administração baseado na New Institutional Economics (Nova Economia Institucional - NIC) e no modelo de gestão empresarial. A primeira base observa a reforma administrativa construída pela transparência, escolha e incentivo estrutural, enquanto a base empresarial visa a profissionalização, tecnicidade e o aumento do desempenho da administração pública (HOOD, 1991).

Um expoente da NPM trata-se de Dwight Waldo. Segundo Waldo (1964), a administração está ligada à cooperação da ação humana, em que a palavra cooperação está voltada para o atingimento de resultados, ou seja, pessoas se juntam para alcançar um propósito. Isto significa que essa cooperação não é necessariamente advinda de boa vontade, sendo que o importante é que a ação conjunta leve ao resultado. Dessa forma o autor descreve a administração como "um tipo de esforço humano cooperativo que possui um alto grau de racionalidade" (WALDO, 1964, p. 10). 
Segundo Silva e Mattia (2016) a administração pública é influenciada pela abordagem da administração científica, sendo seu desenvolvimento baseado em uma abordagem neoliberal, aumentando a busca por eficiência e resultados, atingimento de metas, e padronizações dos procedimentos para se obter qualidade. Para Waldo (1964, p. 22) "a ideia central de administração pública é a ação racional, definida como a ação corretamente calculada para realizar determinados objetivos desejados". Entretanto, as necessidades de uma sociedade são heterogêneas e complexas, exigindo do gestor maturidade no momento da tomada de decisão.

De acordo com Waldo (1964), a complexidade do setor público está relacionada com a heterogeneidade entre os contextos culturais. Heterogeneidade cultural, diferença de classes sociais, situação financeira do governo, arrecadação, nível de pobreza da sociedade, entre diversos outros fatores, contribuindo para o distanciamento entre a administração no setor privado e a administração pública torna a administração pública ainda mais complexa. Nesse contexto, muitas das vezes, por questões de necessidade, buscando superar os obstáculos e dificuldades que permeiam os caminhos organizacionais, sejam essas organizações públicas ou privadas, a cooperação surge como opção na tentativa de solucionar problemas. Essa cooperação entre os atores pode levar à criação de redes organizacionais, onde os membros das redes possuem um mesmo propósito. No entanto, não se pode compreender as redes no âmbito público da mesma forma que no âmbito privado, exigindo uma orientação diferente desses dois contextos.

Uma segunda abordagem da administração pública inspirada na visão empresarial, consiste no movimento reinventando o governo, que tem como perspectiva a necessidade de implantar um governo empreendedor, que visa a busca por processos e tecnologias novas a fim de aprimorar o desempenho da gestão pública, tendo como expoente David Osborne (OSBORNE, 1993).

As diversas abordagens adotadas para aproximar a administração pública com a administração de empresas adotam ainda uma perspectiva weberiana ao considerar a dicotomia entre o ato político e o ato administrativo (DENHARDT; CATLAW, 2017).

Contudo, compreender a administração pública apenas através da racionalidade leva a uma limitação diante da complexidade do setor público. As visões políticas e administrativas se misturam e são complementares, tendo em vista que necessitam entender demandas e gerir recursos para esse fim.

A administração pública deve visar o interesse coletivo, aplicar seus recursos de forma a promover o desenvolvimento, o que muito conflita a visão da eficiência pública. A utilização controlada dos gastos não se torna sinônimo do menor uso dos recursos, mas na capacidade de atenção às necessidades sociais com os recursos disponíveis.

Entender esse fenômeno, por sua vez, pode se tornar complexo, tendo em vista a dificuldade da gestão pública em entender as diversas demandas, criar expertise para atender as necessidades e ter a limitação financeira.

Nesse sentido, torna-se fundamental que a administração pública utilize cada vez mais de mecanismos participativos e de gestão em rede, capaz de compartilhar recursos e experiências e, assim, conseguir atender o pressuposto de eficiência pública sem perder a qualidade dos serviços.

\section{AS REDES ORGANIZACIONAIS}

O avanço tecnológico no período da Revolução Industrial, influenciou não só o desenvolvimento das indústrias, aumentando a capacidade produtiva, mas o comportamento da sociedade. Dessa forma, houve o crescimento da oferta e demanda por produtos, e serviços, alimentando, assim, o consumismo, e 
promovendo o aquecimento da economia. Contudo, a Revolução Industrial, alterou também a vida nas cidades e no campo, uma vez que as pessoas saíam dos campos em busca de oportunidade de emprego.

No início do século XX, o modelo de administração fordista, cuja estrutura organizacional buscava métodos mais rígidos, processos de produção verticais, cuja organização tentava, com o aspecto individual, produzir tudo o que era necessário para que pudesse realizar sua produção. Vale ressaltar, ainda, que nesse período a infraestrutura de transporte e comunicação era precária, ou até mesmo não existia, o que justificava ainda tal processo centralizador.

Com o passar do tempo, o mercado apresentou um crescimento considerável com relação à competitividade, e as necessidades da sociedade tornava-se ainda mais complexas, exigindo da administração momentos de reflexão nas tomadas de decisões (DENHARDT; CATLAW, 2017). No entanto, a escassez de recursos, assim como a competitividade presente no mercado e as necessidades demandada pela sociedade, a necessidade de diminuir a rigidez dos métodos impostos para conseguir reduzir os custos de transações, contribuíram para que as organizações buscassem alternativas na tentativa de superar tais dificuldades (LIMA, 2000). Uma dessas alternativas foi através da cooperação em redes organizacionais.

Segundo Castells (1999, p. 566), pode-se dizer que "rede é um conjunto de nós interconectados", ou seja, um conjunto organizado de unidades, trabalhando em cooperação, em busca de um mesmo propósito. No entanto, os atores da rede possuem interesses próprios, o que pode influenciar a tomada de decisão, para que se possam atingir esses interesses.

Apesar das organizações buscarem a cooperação em redes, a fim de racionalizar os gastos, ao analisar os objetivos das redes organizacionais, nota-se certa diferença entre as redes públicas das redes privadas. As redes privadas buscam a racionalização dos gastos para ganhar maior capacidade competitiva, visando a obtenção de lucro (ALLEGRETTI, 2006). Já as redes públicas procuram minimizar seus gastos com a finalidade de atender às necessidades sociais as quais o governo não consegue sozinho (LIMA, 2000).

As redes públicas, em específico as redes de movimentos sociais, para Scherer-Warren (2008, p. 515), se "caracterizam por articular a heterogeneidade de múltiplos atores coletivos em torno de unidades de referências normativas, relativamente abertas e plurais". Essa pluralidade de atores e interesses criam maior força no sentido de encontrar um campo de disseminação de ideias convergentes para o bem coletivo. Suas ações visam intensificar sua influência e capacidade de utilização de recursos, experiências e aumento da eficiência.

Nesse sentido, nota-se que ao administrar as redes públicas da mesma forma que se gerencia as redes privadas pode apresentar consequências na qualidade do atendimento público por exemplo. Esses problemas advindos da confusão entre público e privado acontece por causa da diferença contextual entre dois setores, conforme visto anteriormente neste ensaio. Silva e Mattia (2016) abordam a necessidade de uma ruptura com o pensamento positivista em relação à administração, e propõe a abertura a um pensamento baseado na criatividade.

A utilização de redes abriu espaço para que as organizações trocassem informações sobre determinados assuntos, auxiliando-as na tomada de decisões diante o mercado competitivo e das dificuldades enfrentadas pela sociedade. Dessa forma, pôde-se melhorar a capacidade intelectual das organizações, contribuindo, por exemplo, para a elaboração do planejamento estratégico da organização, com a previsão de crises ou oportunidades, ou em adquirir conhecimento sobre algumas limitações da sociedade.

Assim, Costa, Nascimento e Tinôco (2011, p. 140), destacam a formação de consórcios intermunicipais no contexto de redes organizacionais, por obedecer "aos interesses dos municípios 
consorciados de uma dada região, que entre si determinam as prioridades e os modos de formação". Para Freitas e Oliveira (2015, p. 339), "uma das formas das pequenas cidades lidar racionalmente com os problemas apontados acima tem sido por meio das associações dos municípios para implementação de políticas públicas". Assim, os consórcios intermunicipais atuam na busca do atendimento às necessidades sociais. Suas ações possibilitam, além do atendimento ao público, melhoria da gestão e capacidade de negociar com fornecedores, tendo efeito prático em todo o sistema, não somente à administração pública.

Nesse contexto, Costa, Nascimento e Tinôco (2011, p. 141), definem os Consórcios Intermunicipais como "instituições nas quais os atores políticos decidem cooperar entre si para solucionar problemas de comum interesse e em áreas específicas, com o objetivo de atender às demandas locais". Existem vários tipos de consórcios intermunicipais, como os de saneamento, de energia elétrica, de construção de estradas e de saúde.

Especificamente na área da saúde pode-se apontar desafios importantes, tais como a escassez de recursos financeiros e mão de obra especializada para o atendimento da população, o que dificulta a ação individual do governo em resolver os problemas relacionados à esta área. Assim, os CIS tentam complementar as políticas públicas de saúde, buscando o acesso ao atendimento através da racionalização dos gastos, trabalhando de modo descentralizado.

\section{CONSÓRCIOS INTERMUNICIPAIS DE SAÚDE}

A implementação e gerenciamento de políticas públicas de saúde apresentam alto grau de complexidade, sobretudo ao se considerar a dificuldade de se prestar um serviço de qualidade para a população, atendendo a todas as necessidades básicas da sociedade e ao mesmo tempo, com recursos escassos.

Seria ingênuo dizer que saúde se trata apenas de ausência de doenças, seu conceito abrange uma complexidade que vai além desta definição, o significado de saúde está ligado a um completo bem-estar físico, mental e social (WHO, 1946). Huber et al. (2011) consideram a saúde como a capacidade de adaptação e autogerenciamento do ser humano, considerando os domínios físico, mental e social.

A saúde é ainda tratada pela constituição brasileira como o direito de todos e dever do Estado, por meio de políticas sociais e econômicas, a redução de doenças e agravos, bem como o acesso universal e igualitário aos seus serviços (BRASIL, 1988).

A saúde pública brasileira se encontra em uma situação preocupante, considerando a grande demanda por tais serviços, resultando na superlotação de hospitais, demora nas filas de espera por atendimento. Dentre os desafios do Sistema Único de Saúde (SUS), destacam-se a necessidade de investimentos para a ampliação da oferta dos serviços, as disparidades regionais relacionadas à disponibilidade de profissionais de saúde, e a relação público-privado na oferta dos serviços de saúde (VIACAVA et al., 2018). Para Reis e Diehl (2015), a prestação do serviço de saúde em alguns municípios não é feita adequadamente, exigindo dos líderes, alternativas para tentar resolver este problema. Nesse sentido, os CIS buscam a minimização de tais problemas presentes no setor de saúde.

De acordo com as Leis Orgânicas da Saúde nº 8.080 de 1990 (BRASIL, 1990a) e nº 8.142 de 1990 (BRASIL, 1990b), os municípios podem se organizar e formar consórcios a fim de desenvolver ações conjuntas para a prestação de serviço da saúde pública. Seria um modo de complementação do sistema de saúde.

Os consórcios públicos não são exclusividades da política de saúde, podendo ser vista em serviços outros serviços sociais, tais como educação e assistência social. Além do modelo de consórcios públicos, há ainda parcerias público-privadas de concessão de espaços a fim de melhorar os serviços prestados e 
reduzir os custos da administração pública, tais como as concessões em rodovias, metrôs e estádios de futebol.

Segundo Gerigk e Pessali (2014, p. 1526) "os CIS foram imaginados como institucionalidades que conjugam os entes municipais para viabilizar o acesso de seus munícipes ao atendimento especializado na área de saúde". De acordo com Schneider (2001, p. 52), considerando as "dificuldades de gerência, e de escassez de recursos, os Consórcios Intermunicipais de Saúde (CIS) nascem como alternativas para a efetiva municipalização das ações e dos serviços de saúde, seguindo os princípios do SUS". Nesse sentido, pode-se entender que os CIS são redes de municípios voltadas para atender às necessidades da sociedade com relação à saúde.

Essas redes intermunicipais acontecem normalmente entre cidades vizinhas, por questão de proximidade. No entanto, esta cooperação não se justifica apenas pela distância física entre os municípios estando relacionada também a propósitos comuns dos municípios, que buscam racionalizar os recursos para atender às populações das cidades consorciadas, como a compra de um equipamento, ou a criação de um hospital, cuja capacidade de atendimento seja abrange a rede.

Contudo, existe um outro fator que leva a criação dos CIS além de atender às necessidades da sociedade, porém, este voltado para um modelo patrimonialista, buscando atender interesses particulares dos gestores, possibilitado assim, um mecanismo de se praticar corrupção, como superfaturamento de serviços e equipamentos, desvio de recursos públicos. De acordo com Lima (2000, p. 987), a conformação dos CIS "pode estar acompanhada de interesses clientelistas de gestores ou comprometida com o aumento da 'resolutibilidade' do serviço de saúde de um determinado município". Tal fator agrava ainda mais a situação precária do setor de saúde no Brasil.

Juridicamente falando, o Consórcio Intermunicipal de Saúde caracteriza-se como pessoa jurídica civil de direito privado (LIMA, 2000), o que faz pensar sobre a forma de administração que deve ser feita. Ao refletir sobre tal abordagem, pode haver críticas ao considerar que a gestão dos CIS deve ser como em empresas, aplicando a racionalização dos recursos, a fim de se alcançar eficiência e resultados, estabelecendo metas para a garantia do serviço prestado. Contudo, pode ser um erro pensar desta forma, uma vez que a sociedade é quem iria contemplar a prestação destes serviços. Neste ponto, nasce a dicotomia: administração pública e administração privada, na gestão dos CIS.

Para melhor entender sobre como deve ser feita a administração dos Consórcios Intermunicipais, propõe-se conhecer primeiramente sua estrutura, que é composta por: i) Conselho de Prefeitos: responsável pela condução político-administrativa do consórcio, é formado por políticos (que por vezes podem tomar decisões baseadas em interesse pessoal, reprimindo o interesse social); ii) Conselho Executivo, na maioria dos casos formado pelo Secretário Municipal de Saúde ou por um técnico que represente o governo local, cujas atribuições sejam de conhecimento específico da área da saúde; iii) Conselho Fiscal ou Conselho Curador, onde é feita a discussão e fiscalização interna dos encaminhamentos institucionais (LIMA, 2000).

Além de analisar sua estrutura, deve-se levar em consideração que os CIS lidam com recursos financeiros públicos. A racionalização destes recursos deve ser feita sem afetar a qualidade da prestação do serviço para a sociedade.

Após esta discussão aqui apresentada, pode-se considerar que, apesar de tratar-se de pessoa jurídica de natureza privada, a complexidade das necessidades da sociedade, somada ao fato dos recursos serem de natureza pública, administrar os CIS como se fosse uma rede privada poderia levar a uma interpretação equivocada, podendo gerar consequências prejudiciais ao bem-estar social. Esta afirmação encontra respaldo nas palavras de Lima (2000, p. 987), que sugere que "os princípios básicos para a administração de um consórcio devem ser os que regem a administração pública”. Este argumento pode 
ainda ser endossado com base nos princípios da administração pública, previsto na Constituição, que são: eficiência, legalidade, impessoalidade, moralidade, publicidade (BRASIL, 1988).

De acordo com Silva e Mattia (2016, p. 1063), o contexto histórico da administração, partindo do modelo Científico, "pode trazer elementos centrais para o campo da administração pública, no entanto, não deve ser analisado como uma corrente cujos elos são intransponíveis no tocante à sua adaptação e mesmo aperfeiçoamento". Desse modo, considera-se a diferença dimensional entre o setor privado e o setor público.

Neste caso, diante do conflito entre público e privado, os CIS necessitam de um processo de gestão pautada no ordenamento público, uma vez que se emprega recursos oriundos de fontes públicas com a finalidade de atender a demanda da sociedade, mesmo quando necessita de utilizar de ferramentas privadas para racionalização das atividades e aplicação eficiente desses recursos.

\section{CONSIDERAÇÕES FINAIS}

Este ensaio teórico abordou em sua temática os CIS, buscando analisar sobre a situação dicotômica entre a administração no setor público e no setor privado, e assim refletir sobre possíveis consequências de se adotar técnicas e ferramentas de gestão empresarial nesse tipo de consórcio.

Diante do exposto, pode-se perceber a importância da formação dos CIS no combate à precariedade do acesso ao atendimento da população que busca por tratamento de saúde mais rápido e de mais qualidade. Contudo, mesmo com a formação dos CIS, a área de saúde pública ainda sofre com muitas limitações. Dessa forma, percebe-se que apesar desses consórcios contribuírem para a minimização dos problemas relacionados à saúde pública, ainda se está longe da solução, devido à complexidade de tais problemas.

A indefinição quanto à abordagem a ser aplicada (pública ou privada) pode agravar ainda mais a situação, se caso os esforços administrativos não se concentrarem no fator que irá realmente melhorar a qualidade do atendimento à saúde. A abordagem taylorista da busca pela eficiência pode influenciar positivamente em relação aos custos e despesas dos CIS. No entanto, deve-se ter a preocupação de que essa racionalização dos gastos não pode sobrepujar as necessidades da sociedade, nem a qualidade do atendimento. A busca pela eficiência deve ser um fator que complementa e que irá contribuir para o atingimento da qualidade do atendimento na saúde pública, e não um fator principal a ser buscado.

Contudo, a escassez de recursos financeiros, materiais e humanos necessários ao atendimento da saúde é um desafio para a gestão pública, o que motiva a busca de alternativas como a prática de cooperação feita através da formação de CIS na tentativa de minimizar o sofrimento dessas pessoas.

O fato é que, os problemas relacionados à saúde abarcam tamanha complexidade que não cabe nas linhas deste ensaio teórico. No entanto, é pertinente a necessidade de se fazer uma reflexão sobre o tema abordado, apontando as dificuldades do setor de saúde, exigindo uma administração mais complexa do que a proposta da gestão privada. Portanto, necessita-se de uma gestão mais flexível e mais apropriada para superar os problemas encontrados, não só na área da saúde, mas no setor público como um todo. Nesse caso, possibilitar maior diálogo com a sociedade, compreender suas demandas e buscar uma gestão participativa torna-se um instrumento importante para a criação dessa flexibilidade da gestão pública, bem como no melhor atendimento à população.

Para estudos futuros, portanto, recomenda-se que se analise empiricamente as relações entre os CIS e sua capacidade de prestar serviços de saúde, analisando ainda como a administração pública tem realizado a gestão destes, bem como o uso de ferramentas gerenciais, tomadas dos modelos privados, 
afetam estes serviços.

\section{REFERÊNCIAS}

ALLEGRETTI, R. D. F. Mecanismos organizacionais horizontais em consórcios de exportação: estudo na indústria moveleira. 2006. 184 f. Dissertação (Mestrado em Administração e Negócios) Faculdade de Administração, Contabilidade e Economia, Pontifícia Universidade Católica do Rio Grande do Sul, Porto Alegre. AXELROD, R. M. The evolution of cooperation. New York: Basic Books, 1984.

BRASIL. Constituição da República Federativa do Brasil. Brasília: Senado, 1988.

BRASIL. Lei no 8.080, de 19 de setembro de 1990. Diário Oficial da República Federativa do Brasil, Brasília, Seção 1, 20 set. 1990a.

BRASIL. Lei no 8.142, de 28 de dezembro de 1990. Diário Oficial da União, Brasília, DF, 31 dez. 1990 b. Disponível em: <http://www.planalto.gov.br/ccivil_03/leis/L8142.htm>. Acesso em: 01 jul. 2017.

BRAVERMAN, H. Trabalho e capital monopolista: a degradação do século XX. Rio de Janeiro: Zahar Editores, 1977.

CASTELLS, M. A Sociedade em Rede. 8. ed. São Paulo: Paz e Terra, 1999.

CHIAVENATO, I. Introdução à Teoria Geral da Administração: uma visão abrangente da moderna administração das organizações. 7. ed. Rio de Janeiro: Elsevier, 2003.

COSTA, A. C. R.; NASCIMENTO, A. B. F. M.; TINÔCO, D. S. Análise do consórcio de produção e abastecimento (CINPRA) do Maranhão à luz dos teóricos das redes organizacionais. Holos, Natal, v. 3, p. 138-155, 2011.

DENHARDT, R. B.; CATLAW, T. J. Teorias da Administração Pública. 2. ed. São Paulo: Cengage Learning, 2017.

FRANÇA FILHO, G. C. Para um olhar epistemológico da administração: problematizando o seu objeto. In: SANTOS, R. S. A administração política como campo do conhecimento. São Paulo: Mandacaru, 2004. p. 119-143.

FREDERICKSON, H. G. Comparing the reinventing government movement with the new public administration. Public Administration Review, 56, n. n. 3, jun. 1996. 263 - 270.

FREITAS, B. R.; OLIVEIRA, A. R. Avaliação dos consórcios intermunicipais de saúde da Zona da Mata mineira: uma análise sob a ótica dos gestores de saúde. Holos, Natal, v. 3, p. 338-353, 2015.

GERIGK, W.; PESSALI, H. F. A promoção da cooperação nos consórcios intermunicipais de saúde do estado do Paraná. Revista de Administração Pública, Rio de Janeiro, v. 48, n. 6, p. 1525-1543, nov./dez. 2014.

HOOD, C. A Public Management for all seasons? Public Administration, v. 69, n. Spring, p. 3-19, 1991.

HUBER, M. et al. How should we define health? BMJ, v. 343, jul. 2011. Disponível em: <https://doi.org/10.1136/bmj.d4163>. Acesso em: 29 out. 2018.

LIMA, A. P. G. Os Consórcios Intermunicipais de Saúde e o Sistema Único de Saúde. Cadernos de Saúde Pública, Rio de Janeiro, v. 16, n. 4, p. 985-996, out./dez. 2000. 
LODI, J. B. As funções do executivo. Revista de Administração de Empresas, São Paulo, v. 11, n. 3, jul./set. 1971.

OSBORNE, D. T. Reinventing Government. Leadership Abstracts, v. 6, n. 1, p. 1-3, jan. 1993.

REIS, H. C.; DIEHL, C. A. A governança corporativa em consórcios intermunicipais públicos de saúde no Rio Grande do Sul. Revista Eletrônica Gestão e Saúde, v. 6, supl. 3, p. 2162-2197, jun. 2015.

SCHERER-WARREN, I. Redes de movimentos sociais na américa latina: caminhos para uma política emancipatória? CADERNO CRH, Salvador, v. 21, n. 54, p. 505-517, Set./Dez. 2008.

SCHNEIDER, A. Os Consórcios Intermunicipais de Saúde no Estado do Rio de Janeiro. Physis: Revista de Saúde Coletiva, Rio de Janeiro, v. 11, n. 2, p. 51-66, 2001.

SILVA, R. R. C. C.; MATTIA, C. Ciência administrativa e gestão pública: uma crítica à primazia do privado em relação ao público. Cadernos EBAPE, Rio de Janeiro, v. 14, n. 4, p. 1054-1065, out./dez. 2016.

SOBRAL, F.; PECI, A. Administração: teoria e prática no contexto brasileiro. São Paulo: Pearson Prentice Hall, 2008.

VIACAVA, F. et al. SUS: oferta, acesso e utilização de serviços de saúde nos últimos 30 anos. Ciência e Saúde Coletiva, Rio de Janeiro, v. 23, n. 6, p. 1751-1762, jun. 2018. Disponível em: <http://dx.doi.org/10.1590/1413-81232018236.06022018>. Acesso em: 30 out. 2018.

WALDO, D. O que é administração pública? In: WALDO, D. O estudo da Administração Pública. Rio de Janeiro: Centro de Publicações Técnicas da Aliança Missão Norte-Americana de Cooperação Econômica e Técnica no Brasil (USAID), 1964.

WHO. Constitution of the World Health Organization. Genebra: World Health Organization, 1946. 